\title{
Studies on pod and bean values of Theobroma cacao L. in Nigeria. II. Number of beans per pod, with special reference to the natural pollination process
}

\author{
H. Toxopeus ${ }^{1}$ and V. J. Jacob
}

Foundation for Agricultural Plant Breeding (SVP), Wageningen, the Netherlands 1 Cocoa Research Institute of Nigeria (CRIN), Ibadan, Nigeria

Received: 30 April 1970

\section{Summary}

The number of beans in a cacao pod is a component of pod value and as such an important yield factor. Studies on open pollinated pods harvested from monoclonal, biclonal and polyclonal plots and four Amazon seedling trees over various periods show that season, genotype and their interaction have a significant effect on number of beans per pod. The character shows a high variability as a result of the natural pollination process. The excessive variation observed in the number of beans of pods from the clone $\mathrm{Na} 32$ in a biclonal plot could be attributed to its self-incompatibility, location and flowering pattern.

\section{Introduction}

The amount of cured cocoa produced annually per acre is the ultimate interest of the cocoa farmer. This yield is a function of number of pods produced per acre, and pod value. Pod value is the amount of cured cocoa produced per pod and this is the product of the mean number of beans per pod, $(\overline{\mathrm{N}})$ and mean cured bean weight. The number of beans per pod $(\mathrm{N})$ is the most important but highly variable component of the pod value (Toxopeus and Jacob, 1969).

Pound (1933) concluded from his study of the variation in characters of farmers' cocoa in Trinidad that 'bean number is an unreliable quantity for characterization of individual trees within the limits of practical sampling...'

This limit was put at 30 pods per sample and it is used for selection purposes throughout the world, but the almost excessive variation of $\mathrm{N}$ has never been further investigated.

This paper presents a quantification of this variability and attempts to explain some of the observations in terms of cultivar, flowering periodicity and self-incompatibility. The object was to arrive at a better understanding of the causes of the variability which might lead to suggestions for improved use of $\mathrm{N}$ as a selection criterion.

1 Formerly: Cocoa Research Institute of Nigeria (CRIN), Ibadan, Nigeria. 


\section{Materials and methods}

The beans in each open pollinated pod, harvested from four F2 Amazon seedling trees and from trees in a monoclonal, a biclonal and a polyclonal plot were counted. The number of pods observed, dates of harvest and the particulars of clones or trees are given below.

Monoclonal plot. 475 pods were harvested in the main crop on 9th November, 1964 from trees of self-compatible clone N38 in the centre of a one-acre monoclonal plot (W2/1) planted in 1948. The trees are all well developed with a continuous canopy.

Biclonal plot. 15 pods were harvested from each of two Upper Amazon clones: Parinari 35 and Nanay 32, planted in 1957 in alternate rows in a one-acre plot (W17/1) surrounded by a guard row of $\mathrm{Na} 32$ trees. Both clones are considered self-incompatible (Knight and Rogers, 1955) and of the 25\% non-fusion type (Cope, 1962). Pods were harvested from the centre of the plot in March, April, May, November, December 1964 and January 1965.

Polyclonal plot. 16 pods were selected at random from a batch of 30 pods harvested at 3 weekly intervals in the period 1 March 1964 to 31 March 1965 from 12 selfcompatible Amelonado/Trinitario clones.

Amazon trees. 16 pod samples were taken at random from the harvests of four $\mathrm{F} 2$ Amazon trees (W4/284, W4/519, W4/714 and W6/718) during the light and main crops for four years: 1963/64, 1964/65, 1965/66, 1967/68. These trees planted in 1950 originated from open pollinated seeds from selected Upper Amazon progenies in the Trinidad Introduction area in Tafo, Ghana.

\section{Results}

The frequency distribution of number of beans per pod in 475 pods harvested from trees in the monoclonal block is shown in Fig. 1. The distribution is skewed and tails off towards the low frequency classes.

The $\overline{\mathrm{N}}$ of the sample of 16 pods harvested on ten different dates from clones in the polyclonal plot is presented in Table 1 . The variance due to clones, harvesting dates and the interaction between clones and harvesting dates were significant $(\mathrm{P}<0.001)$. The main peak of $\bar{N}$ occurs between October and early December after which it declines, it was preceded by a second but lower peak in April, this general pattern was followed by all the clones except N38. The degree of response to seasonal effect appears to be different from one clone to another. The clones can be grouped into two categories on the basis of their lowest number of beans observed in any one pod.

Clones NT164, NT655, NT39, NT284, HN268, C4 and S36 had their lowest N between 5 and 8 and clones NT216, NT310, NT218, NT118 and N38 between 10 and 12 , and the highest $\mathrm{N}$ ranged between 48 and 51 . The lowest $\mathrm{N}$ at different harvesting dates during the main crop (October and January) ranged from 10 to 14 and during the rest of the year from 5 to 8 .

The mean number of beans in samples of 15 pods harvested on six different dates 


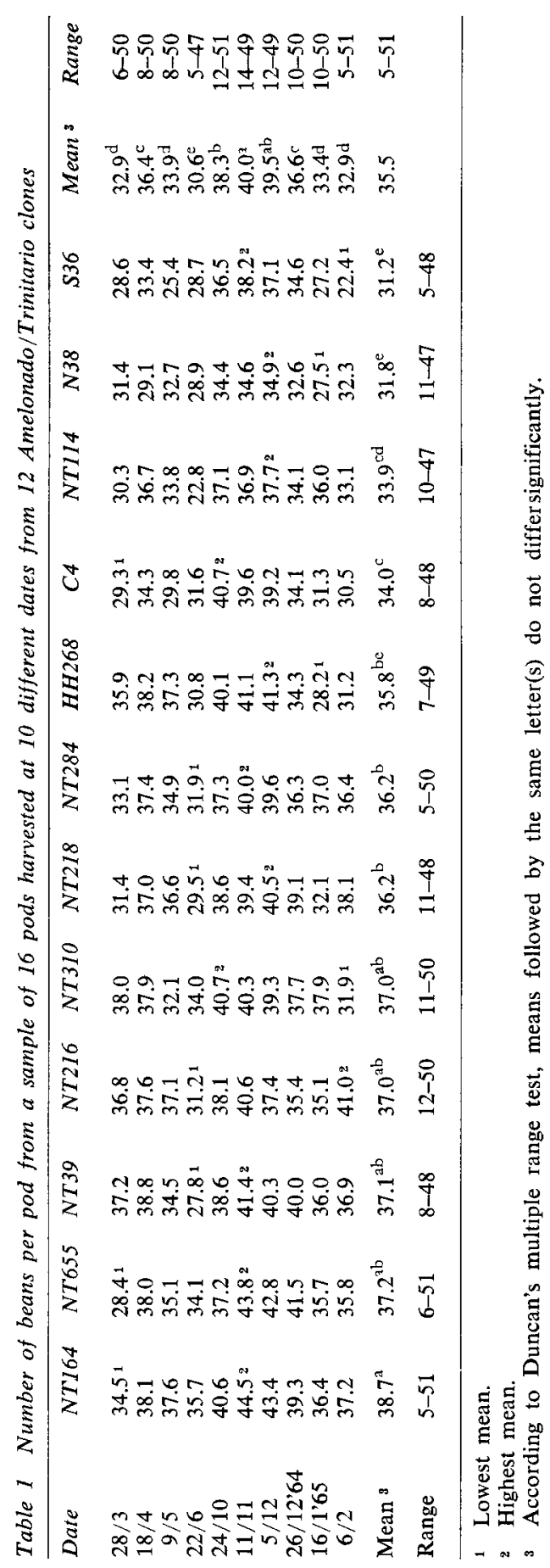




\section{NUMBER OF PODS}

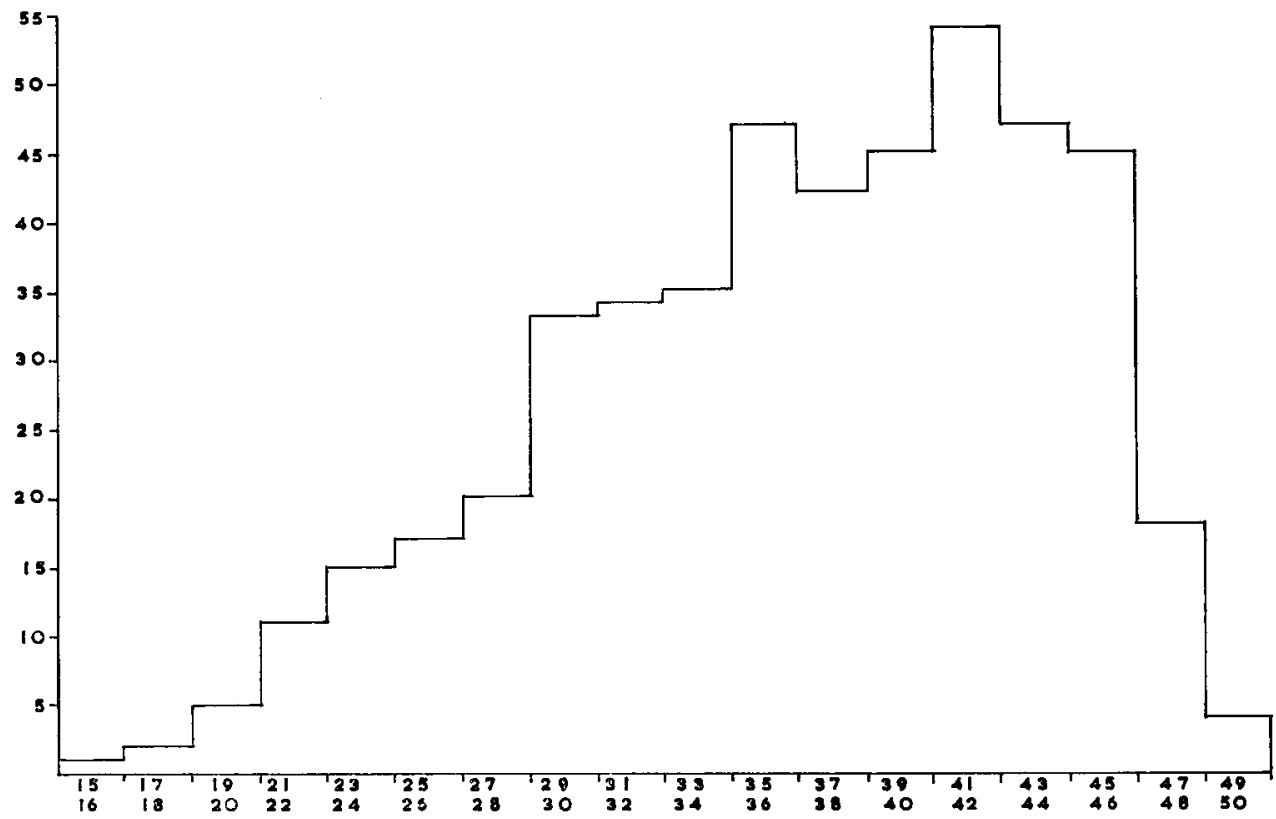

Fig. 1 Class distribution of numbers of beans in 475 pods of clone N38

from trees in the biclonal plot is shown in Table $2 . \overline{\mathrm{N}}$ of samples taken at different harvesting dates was significantly different, $\overline{\mathrm{N}}$ between clones was not. The variance due to samples (individual pods) from Na32 was highly significant (Table 4).

The mean number of beans per pod of four F2 Amazon trees is given in Table 3. The differences between years and between light and main crops were not significant, while the differences between trees were highly significant.

Table 2 Mean number of beans from a sample of 15 pods of Na32 and Pa35 at six harvesting dates

\begin{tabular}{|c|c|c|c|c|c|c|c|c|c|c|c|c|}
\hline & \multicolumn{2}{|c|}{$\begin{array}{c}\text { March } \\
1964\end{array}$} & \multicolumn{2}{|c|}{$\begin{array}{l}\text { April } \\
1964\end{array}$} & \multicolumn{2}{|c|}{$\begin{array}{l}\text { May } \\
1964\end{array}$} & \multicolumn{2}{|c|}{$\begin{array}{c}\text { November } \\
1964\end{array}$} & \multicolumn{2}{|c|}{$\begin{array}{c}\text { December } \\
1964\end{array}$} & \multicolumn{2}{|c|}{$\begin{array}{c}\text { January } \\
1965\end{array}$} \\
\hline & Pa35 & $\mathrm{Na} 32$ & Pa35 & Na32 & Pa35 & $\mathrm{Na} 32$ & Pa35 & $\mathrm{Na} 32$ & Pa35 & $\mathrm{Na} 32$ & Pa35 & $\mathrm{Na} 32$ \\
\hline $\begin{array}{l}\text { Mean for } \\
\text { clones } 1\end{array}$ & 41.7 & 37.4 & 39.9 & 40.5 & 35.2 & 34.3 & 34.0 & 34.9 & 33.7 & 39.6 & 36.5 & 31.1 \\
\hline $\begin{array}{l}\text { Mean for } \\
\text { dates }{ }^{2}\end{array}$ & \multicolumn{2}{|c|}{$39.5^{\mathrm{a}}$} & \multicolumn{2}{|c|}{$40.2^{\mathrm{a}}$} & \multicolumn{2}{|c|}{$34.7^{b}$} & \multicolumn{2}{|c|}{$34.4^{\mathrm{b}}$} & \multicolumn{2}{|c|}{$36.6^{b}$} & \multicolumn{2}{|c|}{$33.8^{\mathrm{b}}$} \\
\hline
\end{tabular}

1 Not significant.

2 According to Duncan's multiple range test, means followed by the same letter do not differ significantly at the $5 \%$ level. 
Table 3 Mean number of beans from a sample of 16 pods of four Upper Amazon trees during light and main crop in four years

\begin{tabular}{|c|c|c|c|c|c|c|c|c|}
\hline \multirow[t]{2}{*}{ Years } & \multicolumn{2}{|c|}{$W 4 / 284$} & \multicolumn{2}{|c|}{$W 4 / 519$} & \multicolumn{2}{|c|}{$W 4 / 724$} & \multicolumn{2}{|c|}{$W 6 / 718$} \\
\hline & $\begin{array}{l}\text { light } \\
\text { crop }\end{array}$ & $\begin{array}{l}\text { main } \\
\text { crop }\end{array}$ & $\begin{array}{l}\text { light } \\
\text { crop }\end{array}$ & $\begin{array}{l}\text { main } \\
\text { crop }\end{array}$ & $\begin{array}{l}\text { light } \\
\text { crop }\end{array}$ & $\begin{array}{l}\text { main } \\
\text { crop }\end{array}$ & $\begin{array}{l}\text { light } \\
\text { crop }\end{array}$ & $\begin{array}{l}\text { main } \\
\text { crop }\end{array}$ \\
\hline $1963 / 64$ & $34.8^{2}$ & $28.8^{1}$ & 35.4 & 28.3 & $39.1^{2}$ & $36.4^{2}$ & $28.0^{2}$ & $15.1^{1}$ \\
\hline $1964 / 65$ & $26.2^{\prime}$ & 36.1 & 31.1 & 29.0 & $22.3^{1}$ & 33.4 & 22.4 & 22.9 \\
\hline $1966 / 67$ & 34.0 & 31.1 & $42.6^{2}$ & $26.6^{1}$ & 30.5 & 32.7 & $21.9^{1}$ & 17.4 \\
\hline $1967 / 68$ & 30.6 & 40.92 & 29.31 & $32.4^{2}$ & 34.3 & $29.2^{1}$ & 24.8 & $24.6=$ \\
\hline $\begin{array}{l}\text { Mean for } \\
\text { crops }\end{array}$ & 31.4 & 34.2 & 34.4 & 29.1 & 31.5 & 32.9 & 24.3 & 20.0 \\
\hline $\begin{array}{l}\text { Mean }{ }^{3} \text { for } \\
\text { trees }\end{array}$ & \multicolumn{2}{|c|}{$32.8^{a}$} & \multicolumn{2}{|c|}{$31.7^{\mathrm{a}}$} & \multicolumn{2}{|c|}{$32.2^{\mathrm{a}}$} & \multicolumn{2}{|c|}{$22.1^{b}$} \\
\hline Range & \multicolumn{2}{|c|}{$11-56$} & \multicolumn{2}{|c|}{$10-51$} & \multicolumn{2}{|c|}{$10-50$} & \multicolumn{2}{|c|}{$5-45$} \\
\hline
\end{tabular}

1 Lowest mean.

2 Highest mean.

3 Means followed by the same letter do not differ significantly at $5 \%$ level.

The variances for the clones and trees are given in Table 4. This shows that the variance due to dates is much greater than that due to clones. The largest variance recorded was for pods of the individual Amazon trees.

\section{Discussion}

The number of beans in the pod is dependent on the number of male gametes that fuse successfully with the female gametes in the ovules of an ovary.

Cacao pollen is very small and sticky and small actively flying midges of the genus Forcipomya (Ceretopogenidae) deposit lumps of pollen on a pistil (Posnette, 1950). A pollen deposit consists of a mixture of pollen from the flowers of various trees previously visited by the midges (Glendinning, 1962).

Table 4 The variances and (in brackets) the degrees of freedom

\begin{tabular}{|c|c|c|c|c|c|}
\hline & \multirow[t]{2}{*}{ N38 } & \multicolumn{2}{|c|}{ Biclonal plot } & \multirow{2}{*}{$\begin{array}{c}\text { Polyclonal } \\
\text { plot }\end{array}$} & \multirow{2}{*}{$\begin{array}{c}\text { Amazon } \\
\text { trees }\end{array}$} \\
\hline & & $\mathrm{Na32}$ & Pa35 & & \\
\hline Samples & $\begin{array}{r}29.77 \\
(29)\end{array}$ & $\begin{array}{c}146.06^{* *} \\
(14)\end{array}$ & $\begin{array}{r}42.86 \\
(14)\end{array}$ & $\begin{array}{r}92.70 \\
(15)\end{array}$ & $\begin{array}{r}69.30 \\
(15)\end{array}$ \\
\hline Clones/trees & & \multirow{2}{*}{\multicolumn{2}{|c|}{$\begin{array}{c}16.80 \\
(1) \\
241.18 * * * * \\
(5)\end{array}$}} & $\begin{array}{l}851.46^{* * * *} \\
\text { (11) }\end{array}$ & $\begin{array}{c}2959.20 * * \\
\text { (3) }\end{array}$ \\
\hline Dates & & & & $\begin{array}{c}1838.17^{* * * *} \\
(9)\end{array}$ & \\
\hline Years & & & & & $\begin{array}{r}229.80 \\
(3)\end{array}$ \\
\hline Crops & & & & & $\begin{array}{r}231.10 \\
(1)\end{array}$ \\
\hline
\end{tabular}


In Indonesia Sutardi (1950) collected in a year 249 specimens of Forcipomya, 87 of which carried 740 cacao pollen grains, van der Knaap (1955) found that $7-10 \%$ of the flowers of a tree have 5 or more pollen grains on the pistil, and more than half of these were found with 20 or more. The fact that lumps of pollen are left on the pistil implies that only the pollen grains in contact with the pistil surface, and those very near will produce tubes and take an active part in the fertilisation process.

Many more pollen grains than available ovules in an ovary (40-70) are needed to fertilize, say, three quarters of the number of ovules. Provided the above data are generally applicable it certainly looks as if a single pollen deposit would usually produce too few pollen tubes to fertilize the majority of ovules in an ovary. This implies that inadequate fertilization is the rule in Theobroma cacao and it is probably the single most important cause of the large variation. The following observation gives more evidence for this hypothesis.

Assuming that the number of flowers and pollinating insects is constant in a cacao plot for a period of 24 hours and that pollination is a random process, a certain number of flowers will receive pollen from more than one insect visit. Opeke and Jacob (1967) showed that ovules stay receptive for at least 4 hours after a first pollination, and van der Knaap (1952) gave evidence that this period was 24 hours. This could well mean that more pollen deposits on a pistil within a period of 24 hours would result in more beans developing in a pod, and it would very well explain the skewness of the distribution in Fig. 1. The number of ovules per ovary counted in N38 flowers was between 39 and 50 (Jacob, 1969), which sets the upper limit for N. Apparently 15 successfully fertilized ovules ( 15 beans) were sufficient for a pod to mature at the time of harvesting (Fig. 1). The tailing towards the low frequency classes can be attributed to the flowers that received one or relatively few pollen deposits.

The seasonal trend of $\overline{\mathrm{N}}$ as is evident from Table 1 has a striking resemblance to the seasonal trend of pod production (Toxopeus and Wessel, 1970). In this case of the self-compatible Amelonado-Trinitario clones the main crop pods produced in October-December were set in May-July when flowering is abundant whilst the light crop pods produced in April-May were set in November-December when flowers are scarce. The difference in $\overline{\mathbf{N}}$ may well be attributed to a difference in pollination frequencies tied up with the availability of flowers in these two periods.

The exceptionally high variance of number of beans in pods of clone Na32 was the more striking because it was not observed in the Pa35 pods (Table 4). A combination of flowering behaviour and incompatibility might explain this as follows.

Both clones are considered to be self-incompatible and belong to the $25 \%$ non-fusion type. This means that on selfing a mean of $25 \%$ of the attempted fusions between gametes fail (Cope, 1962), which induces the ovary to abort. Jacob and Opeke (1967) have shown that clones $\mathrm{Pa} 35$ and $\mathrm{Na} 32$ will give 10 and $2 \%$ set on selfing, respectively. The percentage set of a self-compatible genotype in Nigeria is normally $30 \%$ or over.

Field experience has shown that trees of clone $\mathrm{Na} 32$ flower profusely in most months of the year while the Pa35 trees are notably 'shy' in flowering and a good number of flowers can only be found in a few months of the year. This abundancy of Na32 pollen and scarcity of $\mathrm{Pa} 35$ pollen, respectively, must result in the normal fertilisation of Pa35 flowers and in inadequate fertilisation of Na32 flowers because of self-incompatibility. This might explain the excessive variability of number of beans in Na32 pods. Mean number of ovules per ovary and mean number of beans per pod of Pa35 were 
44.1 and 36.3, respectively, while those of Na32 were 53.9 and 36.3 (Jacob, 1969). This difference between number of ovules and number of beans of $\mathrm{Na} 32$ also points to inadequate fertilization.

\section{Conclusion}

It seems fair to conclude that inadequate fertilization must be the main cause of the variability of number of beans per pod, to the effect that the mean is often considerably lower than should be necessary. It should be an incentive for entomologists and agronomists to find appropriate cultivation practices that would result in more adequate pollination of flowers; yield increases of the order of $10 \%$ are to be expected. The task of the cacao breeder can therefore only be to equip his cultivars with a high potential $\mathrm{N}$; the agronomist should then attempt to realize as much of it as possible in field practise.

One way of assessing potential $\mathrm{N}$ is to count the ovules in a certain number of ovaries of the cultivar concerned. The details of a practical method have yet to be published.

Another assessment of potential $\mathrm{N}$ is to take the highest count from a sample of pods. This does not mean that the beans in all pods of this sample have to be counted because the largest pods will contain the highest number (Toxopeus and Wessel, 1970). The sample should, however, be taken at the time of major pod production of the cultivar and perhaps ought to be about 30 pods in number.

A combination of these two methods of assessment should provide for a sufficiently accurate idea of potential $\mathbf{N}$ of a cultivar although eventually with more experience available ovule counts may turn out to be sufficient.

For the assessment of the mean number of beans per pod realized in field experiment practise it seems advisable, with a view on the skewed distribution of $\mathbf{N}$ as in Fig. 1, not to take the arithmetical mean but the median mean of a sample of pods.

\section{References}

Cope, F. W., 1962. The mechanism of pollen incompatibility in Theobroma cacao L. Heredity 17: 157-182.

Glendinning, D. R., 1962. Natural pollination of cocoa. Nature, Lond. 193: 1305.

Jacob, V. J., 1969. Studies on the number of ovules per ovary. Cocoa Research Institute of Nigeria. Annual Report $1967 / 1968$, p. 60.

Knaap, J. W. van der, 1955. Observations on the pollination of cacao flowers. Rep. 14th Int. hort. Congr. (1955) 1287-1293.

Knight, R. \& H. H. Rogers, 1955. Incompatibility in Theobroma cacao L. Heredity 9 (1) 69-77.

Opeke, L. K. \& V. J. Jacob, 1967. Studies on methods of overcoming self-incompatibility in Theobroma cacao L. Proc. 2nd Int. Conf. Cacao Research (Salvador and Itabuna, Brazil), p. 9497.

Posnette, A. F., 1950. The pollination of cacao in the Gold Coast. J. hort. Sci. 12: 155-163.

Pound, F. J., 1931. The genetic constitution of the cacao crop. 2nd A. Rep. Cacao Res. (Trin.): 10-24.

Sutardi, R. G., 1950. De betekenis van insecten bij de bestuiving van Theobroma cacao L. (The importance of insects in the pollination of Theobroma cacao L.). Summary, tables in English. Archief Koffiecultuur 17: 1-31.

Toxopeus, H. \& V. J. Jacob, 1969. Pod and bean value studies on hand-pollinated pods. Cocoa Research Institute of Nigeria, Annual Report 1967-1968, p. 49-50.

Toxopeus, H. \& M. Wessel, 1970. Studies on pod and bean values of Theobroma cacao L. in $\mathrm{Ni}$ geria, I. Neth. J. agric. Sci. 18: 132-139. 